\title{
Intratumoral Hemorrhage After Endoscopic Third Ventriculostomy for Obstructive Hydrocephalus Caused by Brain Tumors
}

Akira Taguchi ( $\square$ akira.taguchi.0929@gmail.com )

"Hiroshima Daigaku" https://orcid.org/0000-0002-2450-5674

Yasuyuki Kinoshita

Hiroshima University

Vishwa Jeet Amatya

Hiroshima University

Takeshi Takayasu

Hiroshima University

Motoki Takano

Hiroshima University

Ushio Yonezawa

Hiroshima University

Atsushi Tominaga

Hiroshima Prefectural Hospital

Yukio Takeshima

Hiroshima University

Kazuhiko Sugiyama

Hiroshima University Hospital

Fumiyuki Yamasaki

Hiroshima University

\section{Research Article}

Keywords: AT/RT, intratumoral hemorrhage, ETV, obstructive hydrocephalus

Posted Date: March 22nd, 2021

DOI: https://doi.org/10.21203/rs.3.rs-336311/v1

License: (c) (1) This work is licensed under a Creative Commons Attribution 4.0 International License.

Read Full License 
Version of Record: A version of this preprint was published at World Neurosurgery on November 1st, 2021. See the published version at https://doi.org/10.1016/j.wneu.2021.10.161. 


\section{Abstract}

Introduction

Endoscopic third ventriculostomy (ETV) for obstructive hydrocephalus and endoscopic biopsy (EB) for intra- and paraventricular tumors are recognized as standard therapies because of their minimal invasiveness. Although EB-associated hemorrhagic risk has been well documented, reports on the ETVassociated hemorrhagic risk are only few. Therefore, we conducted this retrospective study to review the incidence of hemorrhage due to EB and/or ETV in a single institution.

Material and Methods

We retrospectively reviewed data, including patient characteristics, procedure, pathological findings, and complications, including hemorrhage, of 100 patients with intra- and paraventricular tumors who underwent EB and/or ETV at our institution from 2000 to 2020.

Results

EB and ETV combined surgery (combined group), EB-alone surgery (EB-alone group), and ETV-alone surgery (ETV-alone group) were performed in 44 (44\%), 24 (24\%), and 32 (32\%) patients, respectively, and all procedures were successful. The rates of definitive and suggestive diagnoses in EB were $76.5 \%$ and $23.5 \%$, respectively. Adverse events were observed in six patients. An acute obstruction of the ETV stoma and a transient double vision were observed in the combined group. Two transient aqueductal stenosis/obstructions were recognized in the EB-alone group. Hemorrhage was observed in two patients in the ETV-alone group; these patients developed intratumoral hemorrhage despite ETV-alone surgery. Subsequently, these two patients underwent tumor removal, and the histopathological diagnosis was atypical teratoid/rhabdoid tumor (AT/RT) in both.

\section{Conclusions}

For obstructive hydrocephalus with AT/RTs, physicians must be aware of the risk of postoperative intratumoral hemorrhage after performing ETV.

Trial registration number

E-2385 (2021/3/11)

\section{Introduction}

Endoscopic biopsy (EB) for intra- and paraventricular tumors and endoscopic third ventriculostomy (ETV) for tumor-associated obstructive hydrocephalus are well known as useful therapies. Although these endoscopic surgeries are less invasive and would provide several benefits to patients, surgeons must be aware of their associated risks/benefits. EB is commonly used to treat intra- and paraventricular tumors 
and is superior to stereotactic needle biopsy from the viewpoint of direct visualization [4]. The overall risk of developing hemorrhagic sequelae due to EB for brain tumors is $3.5 \%$, the risk per endoscopic procedure is $2.4 \%$, and the risk for permanent morbidity is $1.2 \%$ [22]. The most frequent complications of ETV are predominantly meningitis/ventriculitis, cerebrospinal fluid (CSF) leaks, and brain or blood vessel injury during surgery $[4,23,28]$. As ETV does not have direct effects against intra- and paraventricular tumors, the hemorrhagic complications due to ETV have been generally reported to be due to damage to surrounding structures [4], and no study has focused on hemorrhagic complications directly caused by ETV.

In the present study, we retrospectively reviewed the data of patients who underwent ETV and/or EB for intra- and paraventricular tumors. We evaluated the incidence of ETV- and EB-related complications and found that two patients developed intratumoral hemorrhage after ETV-alone surgery. Histopathological examination disclosed these tumors as atypical teratoid/rhabdoid tumor (AT/RT) in both patients. We discuss the risk of hemorrhagic complications due to AT/RT and review the difference between AT/RT and other brain tumors.

\section{Materials And Methods}

This retrospective study was approved by our institutional review board (E-2385), and the requirement for written informed consent was waived off.

\section{Patients}

We enrolled the data of 100 patients with intra- and paraventricular tumors who underwent ETV for obstructive hydrocephalus and/or EB for diagnosis at our institution between January 2000 and December 2020. We excluded cases in which the procedure was performed after tumor resection, consecutive craniotomies immediately performed after the procedure, and cases involving procedure for arachnoid cyst. Details regarding age at procedure, sex, ETV and/or EB, time of procedure, pathological findings, and perioperative complications were obtained from medical records. Patients were classified into the ETV and EB combined group (combined group), EB-alone group, and ETV-alone group.

The decision to perform ETV before tumor resection was made on the basis of the clinical state of the patient, findings of the magnetic resonance imaging (MRI) that include the severity of hydrocephalus and/or prepontine CSF space, and response to medical treatment (glucocorticosteroids and diuretics). Patients with obstructive hydrocephalus with tumors at the third ventricle floor underwent EB and extra ventricular drainage (EVD) as they were not suitable for ETV. Such patients were classified into the EBalone group. Craniotomy was performed in all patients in the ETV-alone group within 1-2 weeks after ETV.

\section{Radiological findings}


All patients were evaluated using MRI within 1 week before surgery. The tumor volume was calculated as follows: volume $\left(\mathrm{cm}^{3}\right)=$ width $\times$ height $\times$ depth $/ 2$, where the three parameters were measured using 1.5 (until June 2006) or 3.0 (after July 2006) Tesla MRI unit.

\section{Surgical technique}

A single burr hole was pierced near the front of the left or right coronal suture. A 17.5-Fr sheath (Medikit Peel-Off Introducer, Medikit, Tokyo, Japan) and an endoscope (Olympus, Tokyo, Japan) or a fiberscope (Machida, Chiba, Japan) were inserted. In the combined group, EB was performed first, followed by ETV using a Fogarty balloon catheter or an Expansor balloon catheter (Fuji Systems Corporation, Tokyo, Japan). After ETV, the endoscope was removed, and a piece of absorbable gelatin sponge (Spongel, LTL Pharma, Tokyo, Japan) was placed in the route of the sheath. ETV failure was defined as the need of flow restoration or further unplanned shunt placement.

\section{Pathological diagnosis}

Histopathological diagnosis was defined based on the World Health Organization (WHO) 2016 update. AT/RT was defined based on alterations of either SMARCB1/INI-1 or very rarely SMARCA4/BRG1 $[1,12]$.

\section{Statistical analysis}

Data were statistically represented in terms of frequencies (number of patients) and percentages. Data that were not normally distributed were presented as median and interquartile range (IQR). Statistical analyses were performed using SPSS pro ver. 21.0. Comparison between AT/RTs and medulloblastomas in the ETV-alone group was performed using Fisher's exact test. $P<0.05$ was considered to be statistically significant.

\section{Results}

Table 1 summarizes the clinical characteristics of patients. All ETV/EB surgeries were successfully performed; however, there was a case of ETV failure in a patient with thalamic glioma who underwent a repeat ETV the next day, which confirmed that the leachate from the biopsied tumor was blocking the stoma. The median age of patients was 20 years (IQR, 10-47 years), and the male/female ratio was 65:35. There were 32 patients (32\%) in the ETV-alone group, 24 patients (24\%) in the EB-alone group, and 44 patients (44\%) in the combined group. The proportion of initial surgeries was $84 \%$ (84 patients), and procedures involving EVD, planned ventriculoperitoneal shunt (VPS) placement, and ventricular access device (VAD) comprised 7\% (7 patients), 2\% (2 patients), and 2\% (2 patients), respectively. In the EB-alone group, simultaneously, EVD was performed in four patients (one germinoma and three malignant lymphomas), planned VPS placement was performed in two patients (anaplastic astrocytoma and fibrillary astrocytoma), and VAD was placed in one patient (malignant lymphoma). The median duration of operation was $106 \mathrm{~min}$ (IQR, 87-130 min). The median tumor volume (cm3) was 4.9 (IQR, 1.8-15.1). 
EB was performed in 68 patients. The definitive and suggestive diagnostic rates were $76.5 \%$ (52 patients) and $23.5 \%$ (16 patients), respectively.

Table 2 summarizes details of adverse events in this case series. Overall, adverse events developed in five patients (5\%). In the combined group, one patient (2.3\%) who developed transient double vision had an adverse event of tectal glioma. In the EB-alone group, adverse events developed in two patients (8.3\%), each with malignant lymphoma and germinoma. The lesion in these patients was near the aqueduct, and it was speculated that the tumor debris from the biopsied lesion had blocked the aqueduct. Both patients underwent transient EVD but did not need ETV or VPS placement during their clinical course. In the ETValone group, adverse events developed in two patients (6.3\%). Both these patients developed CTCAE 5.0 grade 2 intratumoral hemorrhage the day after surgery. Craniotomy and tumor resection were performed, and the pathological diagnosis of both tumors was AT/RT.

Table 3 summarizes the pathological findings of patients. Nine patients who underwent EB without subsequent craniotomy remained with suggestive diagnoses. They were diagnosed as low-grade or highgrade gliomas, which could not reach the definitive subtypes of glioma, based on the WHO 2016 update. Total numbers of glioma were $28 \%$ (28 patients) and $39.3 \%$ (11 patients) cases of glioma were highgrade. Germinoma was the most common in this case series (34\%). Among patients with medulloblastoma, most of them underwent ETV alone, and only one patient underwent EB alone for the diagnosis of disseminated recurrent medulloblastoma.

Table 4 summarizes the results of the comparison between AT/RT and medulloblastoma in the ETValone group. Age tended to be higher in the medulloblastoma group. The duration of operation was longer in the AT/RT group. The tumor volume was comparable. The incidence of intratumoral hemorrhage was found to be statistically high in patients with AT/RT $(P<0.05$, Fisher's exact test). We illustrate the representative hemorrhagic cases in Figures 1 and 2.

There were no other adverse event including infection, and the rate of both morbidity and mortality rate was $0 \%$.

\section{Discussion}

In this study, the overall rate of complications due to EB and/or ETV was $5 \%$ ( 5 patients), which is consistent with previous reports, indicating the safety of EB and/or ETV $[4,22,23,28]$. However, intratumoral hemorrhage was observed in two patients; both of these patients were in the ETV-alone group and were diagnosed with AT/RT. There was no other tumors developed intratumoral hemorrhage after ETV. To our knowledge, this is the first report to demonstrate the risk of intratumoral hemorrhage due to AT/RT after ETV for obstructive hydrocephalus. Considering that ETV did not directly damage the tumors, AT/RTs may themselves pose a high risk for intratumoral hemorrhage.

\section{Efficacy of ETV as CSF flow diversion followed by tumor resection}


Several authors have reported that the CSF flow-diverting procedure through EVD or shunt surgery for hydrocephalus makes the subsequent tumor excision more difficult and hazardous [11, 36]. Ideally, performing emergency surgery for hydrocephalus and tumor removal at the same time would be better. However, in the clinical setting, performing early tumor removal via craniotomy may not be possible. For such cases, performing CSF flow-diverting surgery before craniotomy would be a better choice. Furthermore, treating hydrocephalus by ETV could improve the general condition of patients. Corticosteroid therapy, EVD, and VPS placement have been performed as useful treatments for intracranial hypertension [27, 29]. Although corticosteroids may help reduce the posterior fossa swelling, EVD is required, and there remain severe risks due to the increased ICP, such as deterioration in the level of consciousness or visual affection due to papilledema [6]. EVD is commonly used to control ICP for obstructive hydrocephalus, but in the case of pediatric patients, maintaining them in the supine position is often difficult, which may cause difficulty in management until surgery. Precraniotomy VPS placement has several problems, such as upward herniation, infection, shunt malfunction, and abdominal complication $[2,8,9,15,25]$. Therefore, there have been increasing reports on the efficacy of ETV performed as preoperative CSF flow diversion followed by tumor resection $[5,10,32,34,35]$.

\section{Intratumoral hemorrhage due to preoperative CSF flow diversion followed by tumor resection}

There are few reports on intratumoral hemorrhage after EVD, and the actual frequency remains unknown. To the best of our knowledge, the literature reports three cases of medulloblastoma, one case of germ cell tumor, and one case of astrocytoma $[7,13,33,36]$.

On the other hand, El-Gaidi MA et al. reported that $1(1.1 \%)$ of 87 patients and $4(1.9 \%)$ of 214 patients developed intratumoral hemorrhage of posterior fossa tumors after ETV and VPS placement, respectively [6]. Two patients died before tumor resection, and no information on pathology was available. One patient who underwent ETV was a 1.5-year-old boy in whom the subsequent craniotomy revealed astrocytoma. Two patients who underwent VPS placement were a 10-month-old boy and an 8-year-old girl in whom the subsequent craniotomy revealed ependymoma and medulloblastoma, respectively [6].

Kasilwal MK et al. also reported a case of a patient with postoperative (VPS) intratumoral hemorrhage who had hydrocephalus with a basal ganglionic tumor [16]. The cause of the intratumoral hemorrhage was described as a sudden decrease in ICP due to ventricular tapping, resulting in the disturbance of the dynamic balance between the various intracranial contents and causing an increase in cerebral blood flow and vascular congestion [16]. Moreover, the immaturity, fragility, and structural abnormality of tumor vessels were reported as causes of the hemorrhage [6]. In other words, intracranial hemorrhage is induced when the changes in ICP act on vulnerable blood vessels in the tumor.

In the present study, we detected intratumoral hemorrhage only in patients with AT/RT. Hence, AT/RTspecific properties were believed to be the cause.

\section{AT/RT}


AT/RTs are rare malignant intracranial tumors, representing only $1.3 \%$ of primary central nervous system (CNS) tumors in the pediatric population and $6.7 \%$ of CNS tumors in children younger than 2 years of age. These tumors have been categorized into grade 4 of the WHO classification of nervous system tumors published in 2000 [17, 30]. Loss of INI-1 expression is a characteristic feature of AT/RTs. 5 Loss of BRG-1, the product of SMACA4 gene, is rarely observed in patients with AT/RTs [12]. According to the WHO classification of nervous system tumors published in 2016, the diagnosis of AT/RTs requires confirmation of such characteristic molecular defects [21].

Regarding the imaging characteristics of AT/RTs, studies have reported heterogeneity of lesions, intratumoral hemorrhage, hyperintensity on DWI, lower ADC values, presence of a tumor with off-midline location, and peripheral cystic components $[14,15,18,26,37]$. Chan et al. reported that the areas of hemorrhage suggest a vascular tumor, and AT/RTs are hypervascular tumors [3]. Hypervascular tumors have been demonstrated to have massive hemorrhage, and gross total resection is sometimes difficult [24]. A study reported a case of partial resection due to difficulty in reaching the edge of the tumor within the left lateral ventricle and the vascular nature of the tumor, which later developed an uncontrollable postoperative hemorrhage [3]. We preoperatively diagnosed two patients with AT/RT based on brain MRI findings. As the tumors were expected to be easily hemorrhagic, we decided to perform craniotomy at a later date and performed ETV alone for the treatment of hydrocephalus. During the procedure, extreme caution was taken to avoid touching the tumor. Unfortunately, intratumoral hemorrhage postoperatively developed.

\section{Comparison between AT/RTs and medulloblastomas}

There are some previous reports of medulloblastoma or glioma with intratumoral hemorrhage after ETV, but there are no reports of AT/RTs [6]. The majority of AT/RTs exhibit a complex histological pattern, such as choroid plexus carcinoma, germ cell tumor, ependymoma, glioblastoma, or embryonal tumor [1].

Before 2016, positive staining of rhabdoid cells with antibodies to epithelial membrane antigen was used to distinguish AT/RTs from other embryonal tumors [31]. Therefore, patients with AT/RTs may have been included in the category of those with postoperative intratumoral hemorrhage diagnosed with medulloblastoma or high-grade glioma among infant patients in previous reports. In the present study, INI-1 expression was confirmed in all the previous cases of medulloblastoma to clearly distinguish them from those with AT/RTs. Table 3 shows the results of comparison between these cases. The longer duration of operation was influenced by the longer duration until endoscopic introduction in the AT/RT group because of the patients being infants. Although the number of patients was small because of the rarity of the tumor, the incidence of intratumoral hemorrhage after ETV was higher in patients with AT/RTs than in those with medulloblastomas. As there were no patients with intratumoral hemorrhage among patients with any other malignant tumors, we would like to emphasize that ETV for AT/RTs is associated with a higher risk for intratumoral hemorrhage than that for other tumors.

\section{Preventing intratumoral hemorrhage}


To summarize, intratumoral hemorrhage may be caused by a sudden decrease in ICP, and it is more likely to be observed in cases of AT/RTs than in cases of other brain tumors.

In endoscopic procedures, ICP decreases to the same level as that of atmospheric pressure when sheath is inserted, which may pose a risk of developing intratumoral hemorrhage [38]. In contrast, in EVD, a sudden decrease in ICP could be prevented by taking precaution during ventricular tapping. Moreover, the one-way ball valve (Acty valve II, Kaneka Medix, Japan) set at high pressure can release pediatric patients from constraint during ventricular drainage [20]. Therefore, in patients with suspected AT/RTs in preoperative examination, EVD at high pressure may be preferable for ICP control.

\section{Limitation}

There were very few patients with AT/RTs to be statistically examined. We were unable to examine INI-1 expression before 2010 in tumors other than embryonal tumors. Moreover, previous studies have demonstrated intratumoral hemorrhage in not only medulloblastomas but also other high-grade gliomas. The difference between the findings of the present study and those of previous research is unclear because of the lack of detailed description. However, to our knowledge, this is the first report to describe the risk of hemorrhage due to ETV in patients with AT/RTs.

\section{Conclusions}

Intratumoral hemorrhage may be caused by a sudden decrease in ICP and be more likely to be observed in patients with AT/RTs than in those with other brain tumors. In patients with obstructive hydrocephalus with AT/RTs, physicians must be aware of the risk of postoperative intratumoral hemorrhage after performing ETV.

\section{Declarations}

\section{Acknowledgments}

We gratefully acknowledge the work of past and present members of Hiroshima University Hospital.

\section{Funding}

The authors did not receive support from any organization for the submitted work.

\section{Conflicts of interest/Competing interests}

The authors declare that they have no conflict of interest.

\section{Availability of data and material}

The datasets during and/or analyzed during the current study are available from the corresponding author on reasonable request. 


\section{Code availability}

Not applicable.

\section{Authors' contributions}

All authors contributed to the study conception and design. Material preparation, data collection, and analysis were performed by Akira Taguchi, Yasuyuki Kinoshita, Vishwa Jeet Amatya, Atsushi Tominaga and Fumiyuki Yamasaki. The first draft of the manuscript was written by Akira Taguchi. All authors read and approved the manuscript.

\section{Ethics approval}

This study was conducted retrospectively from data obtained for clinical purposes and approved by the ethics committee at Hiroshima University Hospital (E-2385).

\section{Informed consent}

The patient data in this study are completely anonymized, and individual identification is difficult. The research content is displayed in the homepage of our institution.

\section{Consent to participate}

Not applicable.

\section{Consent to publication}

Not applicable.

\section{Acknowledgments}

We gratefully acknowledge the work of past and present members of Hiroshima University Hospital.

\section{References}

1. Biegel JA (2006) Molecular genetics of atypical teratoid/rhabdoid tumor. Neurosurg Focus 20:E11. https://doi.org/10.3171/foc.2006.20.1.12

2. Bryant MS, Bremer AM, Tepas JJ 3rd, Mollitt DL, Nquyen TQ, Talbert JL (1988) Abdominal complications of ventriculoperitoneal shunts. Case reports and review of the literature. Am Surg 54:50-55.

3. Chan V, Marro A, Chainey J, Schmitt L, Das S (2019) Intraventricular atypical teratoid rhabdoid tumour in an adult: a case report and literature review. Folia Neuropathol. 57:295-300. https://doi.org/10.5114/fn.2019.88460 
4. Chowdhry SA, Cohen AR (2013) Intraventricular neuroendoscopy: complication avoidance and management. World Neurosurg. 79:S15.e1-10. https://doi.org/10.1016/j.wneu.2012.02.030

5. El Beltagy MA, Kamal HM, Taha H, Awad M, El Khateeb N (2010) Endoscopic third ventriculostomy before tumor surgery in children with posterior fossa tumors, CCHE experience. Childs Nerv Syst. 26:1699-1704. https://doi.org/10.1007/s00381-010-1180-4

6. El-Gaidi MA, El-Nasr AH, Eissa EM (2015) Infratentorial complications following preresection CSF diversion in children with posterior fossa tumors. J Neurosurg Pediatr. 15:4-11. https://doi.org/10.3171/2014.8.PEDS14146

7. Elgamal EA, Richards PG, Patel UJ (2006) Fatal haemorrhage in medulloblastoma following ventricular drainage. Case report and review of the literature. Pediatr Neurosurg. 42:45-48. https://doi.org/10.1159/000089509

8. Epstein F, Murali R (1978) Pediatric posterior fossa tumors: hazards of the "preoperative" shunt. Neurosurgery. 3:348-350. https://doi.org/10.1227/00006123-197811000-00003

9. Fiorillo A, Maggi G, Martone A, Migliorati R, D'Amore R, Alfieri E, Greco N, Cirillo S, Marano I (2001) Shunt-related abdominal metastases in an infant with medulloblastoma: long-term remission by systemic chemotherapy and surgery. J Neurooncol. 52:273-6. https://doi.org/10.1023/a:1010687121450

10. Frisoli F, Kakareka M, Cole KA, Waanders AJ, Storm PB, Lang SS (2019) Endoscopic third ventriculostomy prior to resection of posterior fossa tumors in children. Childs Nerv Syst 35:789-794. https://doi.org/10.1007/s00381-019-04125-z

11. Goel A (1993) Whither preoperative shunts for posterior fossa tumours? Br J Neurosurg. 7:395-399. https://doi.org/10.3109/02688699309103494

12. Hasselblatt M, Gesk S, Oyen F, Rossi S, Viscardi E, Giangaspero F, Giannini C, Judkins AR, Frühwald MC, Obser T, Schneppenheim R, Siebert R, Paulus W (2011) Nonsense mutation and inactivation of SMARCA4 (BRG1) in an atypical teratoid/rhabdoid tumor showing retained SMARCB1 (INI1) expression. Am J Surg Pathol. 35:933-935. https://doi.org/10.1097/PAS.0b013e3182196a39

13. Hung YC, Lee EJ, Wang LC, Chen HH, Yan JJ, Yu CY (1999) Mixed germ cell tumor presenting as intratumoral hemorrhage: report of a case originated from the pineal region. Kaohsiung J Med Sci. 15:498-503.

14. Jin B, Feng XY (2013) MRI features of atypical teratoid/rhabdoid tumors in children. Pediatr Radiol. 43:1001-1008. https://doi.org/10.1007/s00247-013-2646-9

15. Kanoto M, Toyoguchi Y, Hosoya T, Kuchiki M, Sugai Y (2015) Radiological image features of the atypical teratoid/rhabdoid tumor in adults: a systematic review. Clin Neuroradiol. 25:55-60. https://doi.org/10.1007/s00062-013-0282-2

16. Kasliwal MK, Agrawal D, Sharma BS. Fatal intratumoral hemorrhage following ventriculo-peritoneal shunt. (2008) Turk Neurosurg. 18:436-438.

17. Kleihues P, Cavenee WK (2000) World Health Organization Classification of Tumours. Pathology \& Genetics, Tumours of the nervous system, IARCPress, Lyon, 123-148. 
18. Koral K, Gargan L, Bowers DC, Gimi B, Timmons CF, Weprin B, Rollins NK (2008) Imaging characteristics of atypical teratoid-rhabdoid tumor in children compared with medulloblastoma. AJR Am J Roentgenol. 190:809-814. https://doi.org/10.2214/AJR.07.3069

19. Kubo S, Takimoto H, Hosoi K, Toyota S, Takakura S, Hayashi Y, Ueno M, Morisako T, Karasawa J, Ninaga $\mathrm{H}$, Yoshimine $\mathrm{T}$ (2002) Extracorporeal ventriculoatrial shunt with the use of one-way ball valve. No Shinkei Geka. 30:405-409.

20. Lim ME, Hoffman JA, Kim KS (1999) Recurrent ventriculoperitoneal shunt infection due to nontypeable Haemophilus influenzae. Clin Infect Dis. 28:147-8. https://doi.org/10.1086/517182

21. Louis DN, Perry A, Reifenberger G, von Deimling A, Figarella-Branger D, Cavenee WK, Ohgaki H, Wiestler OD, Kleihues P, Ellison DW (2016) The 2016 World Health Organization Classification of Tumors of the Central Nervous System: a summary. Acta Neuropathol. 131:803-820. https://doi.org/10.1007/s00401-016-1545-1

22. Luther N, Cohen A, Souweidane MM (2005) Hemorrhagic sequelae from intracranial neuroendoscopic procedures for intraventricular tumors. Neurosurg Focus. 19:E9. https://doi.org/10.3171/foc.2005.19.1.10

23. Madsen PJ, Mallela AN, Hudgins ED, Storm PB, Heuer GG, Stein SC (2018) The effect and evolution of patient selection on outcomes in endoscopic third ventriculostomy for hydrocephalus: A largescale review of the literature. J Neurol Sci. 385:185-191. https://doi.org/10.1016/j.jns.2017.12.025

24. McEvoy AW, Harding BN, Phipps KP, Ellison DW, Elsmore AJ, Thompson D, Harkness W, Hayward RD (2000) Management of choroid plexus tumours in children: 20 years experience at a single neurosurgical centre. Pediatr Neurosurg. 32:192-199. https://doi.org/10.1159/000028933

25. McNatt SA, Kim A, Hohuan D, Krieger M, McComb JG (2008) Pediatric shunt malfunction without ventricular dilatation. Pediatr Neurosurg. 44:128-132. https://doi.org/10.1159/000113115

26. Meyers SP, Khademian ZP, Biegel JA, Chuang SH, Korones DN, Zimmerman RA (2006) Primary intracranial atypical teratoid/rhabdoid tumors of infancy and childhood: MRI features and patient outcomes. AJNR Am J Neuroradiol. 27:962-971.

27. Muszynski CA, Laurent JP, Cheek WR (1994) Effects of ventricular drainage and dural closure on cerebrospinal fluid leaks after posterior fossa tumor surgery. Pediatr Neurosurg. 21:227-231. https://doi.org/10.1159/000120840

28. Oertel J, Linsler S, Emmerich C, Keiner D, Gaab M, Schroeder H, Senger S (2017) Results of Combined Intraventricular Neuroendoscopic Procedures in 130 Cases with Special Focus on Fornix Contusions. World Neurosurg. 108:817-825. https://doi.org/10.1016/j.wneu.2017.09.045

29. Rappaport ZH, Shalit MN (1989) Perioperative external ventricular drainage in obstructive hydrocephalus secondary to infratentorial brain tumours. Acta Neurochir (Wien). 96:118-121. https://doi.org/10.1007/BF01456169

30. Rickert CH, Paulus W (2001) Epidemiology of central nervous system tumors in childhood and adolescence based on the new WHO classification. Childs Nerv Syst. 17:503-511. https://doi.org/10.1007/s003810100496 
31. Rorke LB, Packer RJ, Biegel JA (1996) Central nervous system atypical teratoid/rhabdoid tumors of infancy and childhood: definition of an entity. J Neurosurg. 85:56-65. https://doi.org/10.3171/jns.1996.85.1.0056

32. Ruggiero C, Cinalli G, Spennato P, Aliberti F, Cianciulli E, Trischitta V, Maggi G (2004) Endoscopic third ventriculostomy in the treatment of hydrocephalus in posterior fossa tumors in children. Childs Nerv Syst. 20:828-833. https://doi.org/10.1007/s00381-004-0938-y

33. Ryu HS, Jung TY, Han MS, Kim SK, Lee KH (2017) Intraoperative Tumoral Bleeding of Hypervascular Medulloblastoma after Ventricular Drainage: A Case Report. Pediatr Neurosurg. 52:103-108. https://doi.org/10.1159/000452802

34. Sainte-Rose C, Cinalli G, Roux FE, Maixner R, Chumas PD, Mansour M, Carpentier A, Bourgeois M, Zerah M, Pierre-Kahn A, Renier D (2001) Management of hydrocephalus in pediatric patients with posterior fossa tumors: the role of endoscopic third ventriculostomy. J Neurosurg. 95:791-797. https://doi.org/10.3171/jns.2001.95.5.0791

35. Toescu SM, Samarth G, Layard Horsfall H, Issitt R, Margetts B, Phipps KP, Jeelani NU, Thompson DNP, Aquilina K (2020) Fourth ventricle tumors in children: complications and influence of surgical approach. J Neurosurg Pediatr. 23:1-10. https://doi.org/10.3171/2020.6.PEDS2089

36. Vaquero J, Cabezudo JM, de Sola RG, Nombela L (1981) Intratumoral hemorrhage in posterior fossa tumors after ventricular drainage. Report of two cases. J Neurosurg. 54:406-408. https://doi.org/10.3171/jns.1981.54.3.0406

37. Warmuth-Metz M, Bison B, Dannemann-Stern E, Kortmann R, Rutkowski S, Pietsch T (2008) CT and MR imaging in atypical teratoid/rhabdoid tumors of the central nervous system. Neuroradiology. 50:447-452. https://doi.org/10.1007/s00234-008-0369-7

38. Wong TT, Yen SH, Ho DM, Chang FC, Chang KP(2003) Pineal germinoma with intratumoral hemorrhage after neuroendoscopic tumor biopsy. Childs Nerv Syst. 19:769-72. https://doi.org/10.1007/s00381-003-0800-7

\section{Tables}

Due to technical limitations, table 1, 2, 3 and 4 is only available as a download in the Supplemental Files section.

\section{Figures}



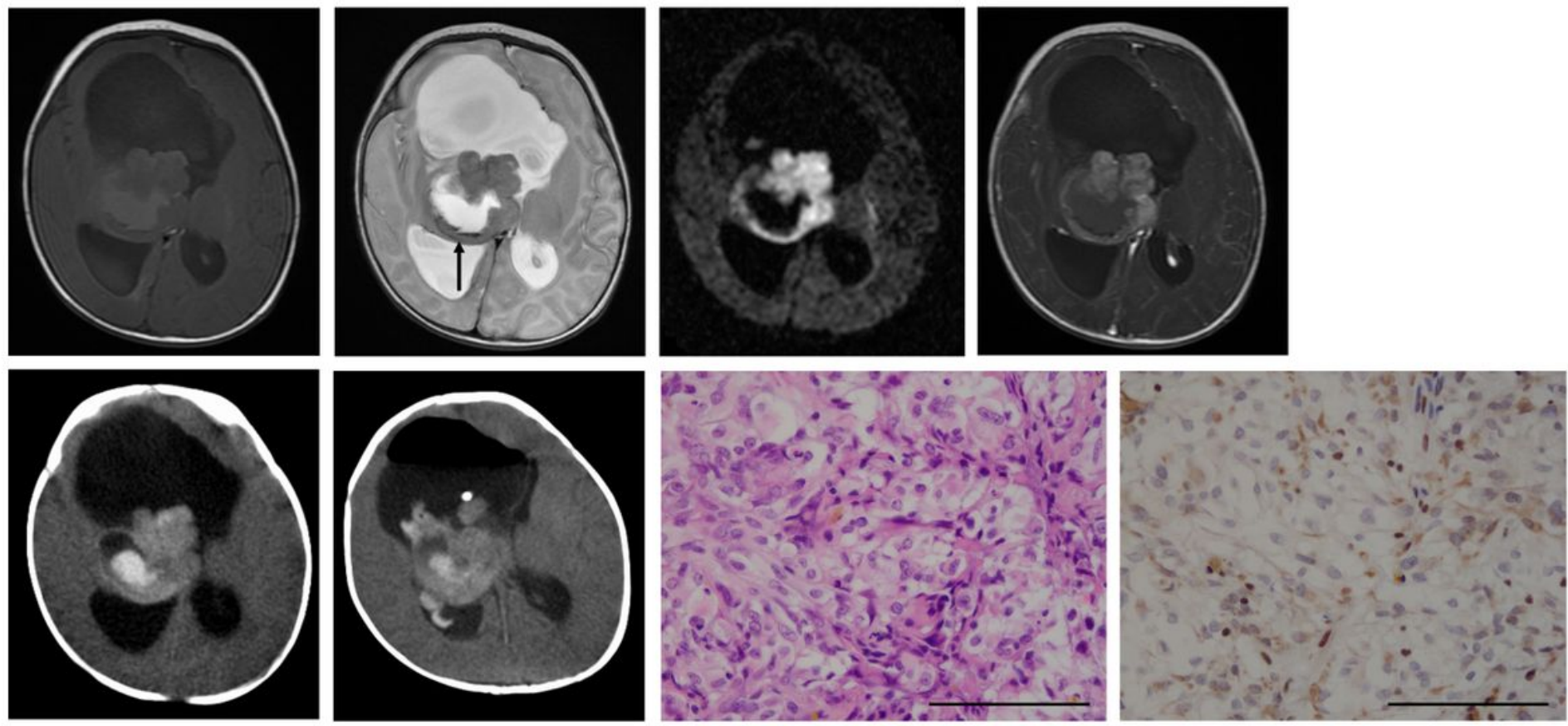

Figure 1

A 0-year-old female patient with supratentorial atypical teratoid/rhabdoid tumor (AT/RT). Aqueduct obstruction due to a large thalamic tumor with intratumoral hemorrhage resulted in ventricular enlargement (A-E). T1- (A) and T2-weighted images (B) show the fluid-fluid level inside the tumor that indicates intratumoral hemorrhage (arrows). Diffusion-weighted image $(b=4000)(C)$ shows the tumor with high cellularity. Contrast-enhanced T1-weighted image depicts the intense but heterogeneous mass (D). Axial computed tomography (CT) image illustrates isodense mass in the thalamus, with a hyperdensity portion suggestive of intratumoral hemorrhage (E). At age 81 days, endoscopic third ventriculostomy (ETV) without tumor biopsy was performed to improve the general condition of the patient. Extraventricular drainage was inserted for prophylaxis against development with recurrent hydrocephalus through unexpected closure of the ETV stoma. During the surgical procedure, the appearance of the tumor did not change. The CT image on the next day after ETV revealed an increase in tumor volume due to an increase in intratumoral hemorrhage with intraventricular hemorrhage $(F)$. The tumor exhibited the histological features of AT/RT with multiple foci of rhabdoid cell proliferations (original magnification, $\times 400$; bar, $50 \mu \mathrm{m})(\mathrm{G})$, and immunohistochemical study shows loss of INI-1 expression (original magnification, $\times 400$; bar, $50 \mu \mathrm{m})(\mathrm{H})$. 

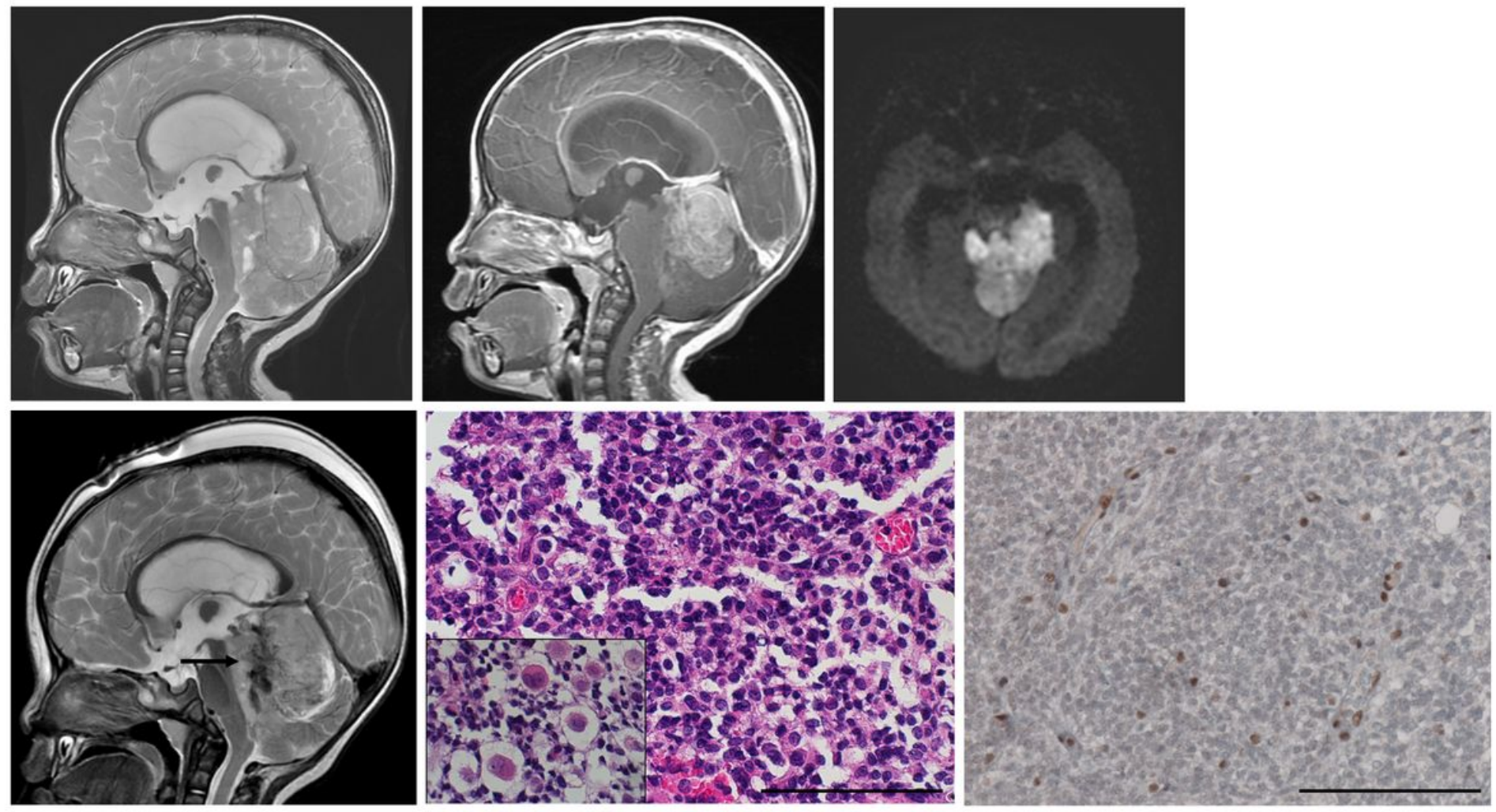

Figure 2

A 2-year-old female patient with infratentorial atypical teratoid/rhabdoid tumor. The patient presented with a marked dilation of ventricles due to obstruction of the aqueduct as observed on brain magnetic resonance imaging $(A-C)$. Sagittal T2- $(A)$ and contrast-enhanced T1-weighted images $(B)$ show the heterogeneous tumor. Diffusion-weighted image $(b=4000)(C)$ shows the tumor with high cellularity. During endoscopic third ventriculostomy, we did not observe tumor appearance. The next morning, the patient started vomiting, and T2-weighted image revealed intratumoral hemorrhage (arrow). Specimens show histological evidence of rhabdoid cells (H\&E; original magnification, $\times 200$; bar, $100 \mu \mathrm{m})(\mathrm{E})$. INI-1 reactivity is negative for tumor cells (original magnification, $\times 200$; bar, $100 \mu \mathrm{m})(F)$.

\section{Supplementary Files}

This is a list of supplementary files associated with this preprint. Click to download.

- table1.xlsx

- table2.xlsx

- table3.xIsx

- table4.xIsx 